\title{
Exploring the Usage and the User Interface of Mobile apps for Donors in Natural Disaster in East Java, Indonesia
}

\author{
Djoni Haryadi Setiabudi1, || Gede Agus Widyadana ${ }^{2}$, and Hui-Ming Teng ${ }^{3}$ \\ ${ }^{1}$ Informatics Department, Petra Christian University Jl. Siwalankerto 121-131, Surabaya 60236, \\ Indonesia \\ ${ }^{2}$ Industrial Engineering Department, Petra Christian University, Jl. Siwalankerto 121-131, Surabaya \\ 60236, Indonesia \\ ${ }^{3}$ Department of Business Administration, Chihlee Institute of Technology, Banciao, Taipei 22005 \\ Taiwan
}

Abstract

Natural disasters occur quite often in Indonesia. Relief can be in the forms of logistics or funds. Indonesian Red Cross is one of the institutions most trusted in distributing donations. Unfortunately, there is still no easy facilitation for donors in transferring funds. An effective system is needed to ease donors in transferring funds using an online

Corresponding Author: I Gede Agus Widyadana gede@petra.ac.id

Received: 16 February 2020 Accepted: 5 March 2020 Published: 10 March 2020

Publishing services provided by Knowledge E

(c) Djoni Haryadi Setiabudi et al. This article is distributed under the terms of the Creative Commons Attribution License, which permits unrestricted use and redistribution provided that the original author and source are credited

Selection and Peer-review under the responsibility of the ICLBI (2018) Conference Committee.

\section{G OPEN ACCESS} application, to guarantee that the funds are not misused, to inform the kind of disasters requiring financial aids or to report the utilization of the aids. Not many researches have been conducted on this subject. Those related to the Human-Computer Interaction in Health Care were focused on patients. The ones in the field of e-commerce were focused on customers. Meanwhile, this research on the case of natural disaster was focusing on donors, which was not quite ordinary. The researches in the case of natural disasters were mostly focusing on the problem of distribution and supply of logistics or searching the nearest locations using GIS. This research aims to explore the user expectations of the mobile apps on the process of donating applying the principles of $\mathrm{HCl}$ such as conveniences, effectiveness, security, completeness of information, feedback, and visibility. The result of this research shows that the expected users with this application could provide quality of information, continuity, ease of access and high security. Developing a mobile application with effective interaction between the application and the users is really a challenge.

Keywords: Human-computer interface; humantarian logistics; donor system.

\section{Introduction}

Due to its geographical location, Indonesia is susceptible to natural disasters, such as volcano eruptions, earthquakes, landslides, flash floods etc. Whenever a natural disaster occurs, the government always sends volunteers to the location together with logistic aids for the disaster victims. There has been a lot of expenses for the deliveries and procurements of those logistics. The government funds are often not enough to cover 
all expenditures for the disaster victims. Thus all parties who handle the disaster victims find every way to do fundraisings from the society who care enough with the fate of the disaster victims. The Indonesian Red Cross, among others, is one of the Government institutions responsible for taking care of those disaster victims.

Although the Indonesian Red Cross has received all kinds of donations, either in the form of logistics or financial aids, still the Indonesian Red Cross prefers financial aids. Logistics can be easily outdated and damaged before being used. Logistics also need lots of spaces to be kept in the warehouse. From the side of donors, the problem is the process of financial funding. They sometimes have doubts about whether the financial aids they donate will go to the right persons or not. The funding process is also often not easy to do. The donors also would like to know how far their donation has been channeled to the disaster victims. They need reports on how those donation has been utilized.

So far the donation funding process, facilitated by the Indonesian Red Cross, has been conducted via ATM of certain banks or transferred via certain banks facilitated by the Indonesian Red Cross website, developed by the Headquarter of the Indonesian Red Cross, Jakarta. The problem faced by the donors, among others, is the complicated process of transferring money. The donors have to upload the evidence of the transfer. The confirmation of receipt also takes a long time. There is no clear report on the utilization of the donation funds. There is actually a third party, indokasih.com, appointed as an intermediary agent on receiving the donation. Still, the process is also complicated. This intermediary agent takes $5 \%$ of the donation funds as fees. It reduces the funds that can be allocated by the Indonesian Red Cross for the disaster victims. Research should be conducted to handle the problem of the Indonesian Red Cross in providing an easy online process for donors in transferring their donation funds.

Not all donors are computer literate persons in using online applications, therefore a user-friendly interface is also needed to ease donors in using the application. Not many researches have conducted on this subject. Those related to the Human-Computer Interaction in Health Care were focused on patients [1]. The researches conducted in the field of e-commerce were focusing on customers who are doing procurement. Meanwhile, researches on the case of natural disaster should focus on donors. So far researches on the subject of natural disasters, were mostly focusing on the problem of distribution and sending of logistics to the disaster areas [2]. The above-mentioned research was focusing on sending logistics to the disaster areas with the aids of convenience stores, but not yet focusing on the funding process. This research is 
conducted will fill the gap of what has not been done at the researches on natural disasters. It will explore the needs of the donors in transferring donation funds using a mobile application for the disaster victims, focusing on the Human-Computer Interface principles. Those principles being explored are conveniences, effectiveness, security, completeness of information, feedback and visibility.

\section{Motivation and related research}

The development of mobile application has been growing so fast during these recent years. With the growing number of smartphone users in the world, people are not using smartphones only as social media such as WhatsApp, Line, WeChat only, but for other purposes as well such as financial transaction, health, and government issues. According to the survey by [3], the number of downloads of mobile applications is 197 000 000, $31.95 \%$ increase from 2016. This fact drives application developers to choose to develop mobile applications compared to web applications. The mobile application has excellent quality such as features on accelerometer, compass, location awareness, and push notification. Based on that fact, this research is more focused on developing a mobile application. Some researches have been conducted related to the use of mobile applications before.

The subject of Human-Computer Interaction is also an interesting and complex subject to be explored as there have been a lot of questions raised. There have also been changes and new findings as time goes by [4]. The research methods being used are considered complex as they are drawn from several different fields. They are modified and thus creating new standards to be researched. Involving humans is also considered as complex. The root of the problems have to be comprehended, the development of Human-Computer Interaction research methods have to be understood and there have some multidimensional problems to be considered.

The research on mobile social application conducted in reference [5] was discussing the satisfaction, habits and customer value perspectives, especially among youth. Some results of this research were to increase the user satisfaction factor by calculating the usability features, especially related to daily activities. The relationship formed through social networks could also develop the habits of the users, especially among young people. Therefore, the information should be better delivered to the users in pictures, not only in text form. 
Serra et al. [6] did some researches on the use of the mobile application for developing m-government, an application for providing services for citizens. By using mgovernment, services were more accessible to the citizens, including disabled people. The offered services, included information access, corruption reduction, efficiency increase, the participation of the community on social activities. The method of HumanComputer Interaction was used to evaluate the performance of the accessibility, both for the target users as well as experts. The evaluation was conducted using Web Content Accessibility Guideline [7]. The result of this research showed that a lot of users had difficulties in accessibility, especially using gestures replacing the use of keyboards.

The research related to health services using mobile application was conducted by [1], on the case of healthcare professional using mobile devices. This research put emphasis on user interfaces. As doctors focus more on patients, not on the system. the bad user interface will create medical errors. They were using the method on Quality in User Measurement Model. The result of the research was successful in aiding doctors to take care of patients faster, and more effective. Thus they managed to do some correction action immediately and there was an increase in productivity. Loads of the doctors were also reduced.

Research on logistics distribution for disaster victims. This research focused on the process of documenting the logistic data and the process of logistics distribution to the location of the disaster victims is conducted by [2]. The donors generally gave their donation in the form of logistics. The donation in the form of financial aids was conducted using bank transfer method, verified manually, not automatically. The importance of funding systems in humanitarian logistics is very important and there are many research related to this area [8]. Financial and logistic aspects are important for humanitarian logistic organizations. Some organizations have budget and stocks constraints, therefore it is important for humanitarian organizations to integrate purchasing costs, multiple freight, budget, capacity and demand constraints [9]. Since Non-Government Organization (NGO) have important role in humanitarian logistic, the cooperation of NGOs improves the donors utility [10].

Therefore, this research is focused on Indonesia Red Cross as one of organization that has ability to collect donation from donors. 


\section{Research methodology}

To get the data of the donor candidates as the respondents. The method of gathering selected data was using questionnaires. They were distributed to 100 respondents randomly in Surabaya, Indonesia. The structure of the questionnaires consisted of two parts. The first part consisted of questions related to the profiles of the respondents such as gender, age, and education background. There were also questions about the habit of using mobile phones and experiences in donating to the Indonesian Red Cross. The profiles of the respondents covered higher education students, professionals, government officers, personnel from private sectors, members of the Indonesian National Army/ members of police corps. As shown in Table 1, the results indicated that $57 \%$ of the respondents were personnel from private sectors and higher education students. In term of gender, $55 \%$ were males and $45 \%$ were females. In term of age, most of the respondents were between $21 \mathrm{yr}$ to $30 \mathrm{yr}$. In term of education, $50 \%$ were senior high school graduated. From the respondents, $95 \%$ had mobile phones and $65 \%$ of them were using their mobile phone to find for information. As for $38 \%$ of them had donated to the Indonesian Red Cross but gave more manually in the form of coupons and a donation box, not donate through the online application.

The second part of the questionnaires included questions on the expectations of the respondents, such as the application features they prefer to use if they donate online to the Indonesian Red Cross. The expectations were divided into five aspects: benefits, ease of access, trust, the quality of information and user interface. The questions on the aspect of benefits were directed to identify what kind of features were expected by the candidate users of the application. Those questions on the aspect of ease of access were focusing on significant issues to be considered to ease the candidate users in using the application. The aspect of trust was directed to get to know whether the candidate users had high hopes on the guarantee of security as this application involves a financial transaction. While the inquiries on the aspect of the quality of information were to gain the knowledge whether the quality information provided by the application was something expected by the candidate users. The aspect of the user interface of the questions had a purpose to identify what kind of user interface will attract the candidate user to use the application to be developed. 
TABLE 1: Data on respondents' occupation

\begin{tabular}{l|c|c|c|c|} 
& Frequency & Percentage & $\begin{array}{c}\text { Valid } \\
\text { Percentage }\end{array}$ & $\begin{array}{c}\text { Cumulative } \\
\text { Percentage }\end{array}$ \\
\hline Government officers & 12 & 12.0 & 12.0 & 12.0 \\
\hline $\begin{array}{l}\text { Personnel of private sectors } \\
\text { Members of Indonesian National Army/Police }\end{array}$ & 13 & 32.0 & 32.0 & 44.0 \\
\hline Corps & 18 & 13.0 & 13.0 & 57.0 \\
\hline $\begin{array}{l}\text { Professionals } \\
\text { Students/higher education students }\end{array}$ & 25 & 25.0 & 25.0 & 100.0 \\
\hline Total & 100 & 100.0 & 100.0 & 18.0 \\
\hline
\end{tabular}

\section{Result and discussion}

There was an opportunity for effective usage of the Indonesian Red Cross Donation Mobile Device Application as $95 \%$ of the respondents had mobile devices. Most of them were using mobile devices for finding information. This profile matched one of the functions of the application which was supposed to give the information needed by the donors. The interaction between the society and The Indonesian Red Cross was quite good, indicated by the fact that $44 \%$ of the respondents had contributed in blood donor activities. There are $59 \%$ of the respondents recognized the function of The Indonesian Red Cross in doing fundraising to support humanitarian activities. On the other hand, there was also a gap to fill as $41 \%$ of the respondents still did not know the function of the Indonesian Red Cross as a support system for humanitarian activities.

Fundraising using a mobile device application also has a good prospect as $61 \%$ of the respondents had never contributed any funds for the Indonesian Red Cross. The ones who contributed were doing the donation using The Indonesian Red Cross coupons or donation box, as indicated in Table 2.

TABLE 2: Those who had /had not donated funds

\begin{tabular}{l|c|c|c|c|} 
& Frequency & Percentage & $\begin{array}{c}\text { Valid } \\
\text { Percentage }\end{array}$ & $\begin{array}{c}\text { Cumulative } \\
\text { Percentage }\end{array}$ \\
\hline Coupons & 20 & 20.0 & 20.0 & 20.0 \\
\hline Donation & 18 & 18.0 & 18.0 & 38.0 \\
\hline Box & 61 & 61.0 & 61.0 & 99.0 \\
\hline Never others & 1 & 1.0 & 1.0 & 100.0 \\
\hline Total & 100 & 100.0 & 100.0 & \\
\hline
\end{tabular}


These two types of donation are local in characteristic. They can only reach out to a relatively small number of donors. Using mobile devices will allow a wide range of reaching out. Another effort of sending donation has also been done via the Indonesian Red Cross website. This website actually can reach out a wide range of users, but not many people have been attracted to visit the website, as only $11 \%$ of the respondents visited the website, as shown at Table 3. On the other hand, $65 \%$ of the respondents were using mobile devices to find for application as visible in Table 4. It seems that people are not interested in finding information in the Indonesian Red Cross web site using mobile devices. This fact indicates that the Indonesian Red Cross needs an information and donation application to be more widely accessed by society. The result of the questionnaires also shows something interesting as nine out of 11 people or $80 \%$ of those who accessed the website, had been giving a donation as pointed out in Table 3 and Table 5.

TABLE 3: Visits to the Indonesian Red Cross Website

Yes
No
Total

\begin{tabular}{c} 
Frequency \\
11 \\
89 \\
100 \\
\hline
\end{tabular}

\begin{tabular}{c} 
Percentage \\
\hline 11.0 \\
89.0 \\
100.0 \\
\hline
\end{tabular}

\begin{tabular}{c} 
Valid Percentage \\
\begin{tabular}{c}
11.0 \\
89.0 \\
100.0 \\
\hline
\end{tabular} \\
\hline
\end{tabular}

\begin{tabular}{|c|}
\hline Cumulative \\
Percentage \\
\hline 11.0 \\
\hline 100.0 \\
\hline
\end{tabular}

TABLE 4: The usage of mobile devices

\begin{tabular}{|l|l|}
\hline Valid & \\
& Finding for information \\
& Music/films \\
& Game \\
& Others \\
\hline & Total \\
\hline
\end{tabular}

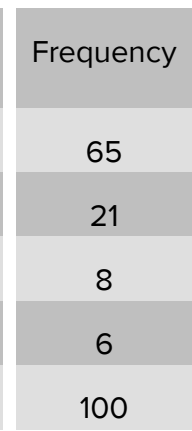

\begin{tabular}{|c|}
\hline Percentage \\
\hline 65.0 \\
\hline 21.0 \\
\hline 8.0 \\
\hline 6.0 \\
\hline 100.0 \\
\hline
\end{tabular}

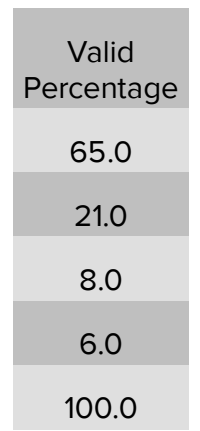

Cumulative Percent 65.0 86.0 94.0 100.0

TABLE 5: Donation via the Indonesian Red Cross website

Valid

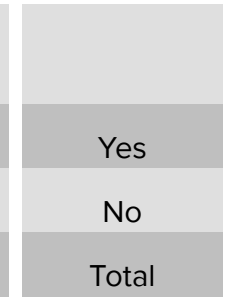

\begin{tabular}{c} 
Frequency \\
\hline 9 \\
91 \\
100 \\
\hline
\end{tabular}

\begin{tabular}{|c|}
\hline Percentage \\
\hline 9.0 \\
\hline 91.0 \\
\hline 100.0 \\
\hline
\end{tabular}

\begin{tabular}{c}
$\begin{array}{c}\text { Valid } \\
\text { Percentage }\end{array}$ \\
9.0 \\
91.0 \\
100.0 \\
\hline
\end{tabular}


It means that those who accessed the website really had the intention of donating. Actually, a lot of people are willing to participate in giving a donation but they do not know the right channel yet. Table 6 shows that $6 \%$ of the respondents were giving a donation to some boards or organizations online. Thus a disaster aid application needs to be carefully designed to run effectively.

TABLE 6: Donation Via Online Application

\begin{tabular}{|c|c|c|c|c|}
\hline & Frequency & Percentage & $\begin{array}{c}\text { Valid } \\
\text { Percentage }\end{array}$ & $\begin{array}{c}\text { Cumulative } \\
\text { Percentage }\end{array}$ \\
\hline Yes & 6 & 6.0 & 6.0 & 6.0 \\
\hline No & 94 & 94.0 & 94.0 & 100.0 \\
\hline Total & 100 & 100.0 & 100.0 & \\
\hline
\end{tabular}

Based on the analysis of the data, the first issue found is that society prefers a donation application with an up to date user interface. The fact that the respondents seldom visited the website of The Indonesian Red Cross shows that the website is not attractive enough compared to the user interface of an online application. In conjunction with the fact that the majority of the respondents were using mobile devices to find information, the second issue comes up on the quality of information delivery. Therefore, a selection of information needed or not needed by society and future donors is very crucial. The third issue to be considered is a challenge of providing an attractive, up to date application, yet not complicated access to the users. The fourth expectation of the respondents is an application, easy to download. The fifth expectation is easy to understand, clear and concise information.

Some interesting findings are detected from the responses of the questionnaires as the respondents did not consider the use of symbols as an important issue. The use of pictures and the right sentences is enough for the respondents. The information on the last donation is also considered essential. This fact shows that the respondents trust the Indonesian Red Cross in managing their donation. Something considered least important is an event-based donation. It shows that respondents generally have the willingness to help universally, disregarding the area of natural disasters or who are the victims of the natural disaster. This kind of findings is an opportunity for the Indonesian Red Cross to do fundraisings in continuity not only during any event of natural disaster. Thus an updated, annual and continual information is needed.

To develop an effective application for the Indonesian Red Cross, the views of the respondents in a different range of age should be put into consideration. As viewed at Table 7, at the range of age under $30 \mathrm{yr}$, either between $17 \mathrm{yr}$ to $21 \mathrm{yr}$ or $21 \mathrm{yr}$ to 
$30 \mathrm{yr}$, the quality of information, ease of use and reliability are three highest variables expected of an application. Meanwhile, the users at the range under $17 \mathrm{yr}$ of age put more emphasis on the ease of use, reliability and the quality of information, as shown in Table 8.

TABLE 7: Descriptive statistics for users at $17 \mathrm{yr}$ to $21 \mathrm{yr}$

\begin{tabular}{|l|c|c|c|c|c|}
\hline & N & Minimum & Maximum & Mean & Std. Deviation \\
\hline Average On Quality & 14 & 3.67 & 5.00 & 4.4762 & 0.44749 \\
\hline Average On Ease & 14 & 3.17 & 5.00 & 4.4405 & 0.56086 \\
\hline Average On Reliability & 14 & 3.00 & 5.00 & 4.3571 & 0.66299 \\
\hline Average On User Interface & 14 & 3.83 & 5.00 & 4.3214 & 0.31666 \\
\hline Average On Benefit & 14 & 3.67 & 5.00 & 4.2857 & 0.36061 \\
\hline Valid N (listwise) & 14 & & & & \\
\hline
\end{tabular}

TABLE 8: Descriptive statistics for users at $\leq 17 \mathrm{yr}$

\begin{tabular}{|l|c|c|c|c|c|}
\hline & $N$ & Minimum & Maximum & Mean & Std. Deviation \\
\hline Average On Ease & 3 & 4.00 & 5.00 & 4.6111 & 0.53576 \\
\hline Average On Reliability & 3 & 4.00 & 5.00 & 4.5000 & 0.50000 \\
\hline Average On Quality & 3 & 4.00 & 5.00 & 4.3333 & 0.57735 \\
\hline Average On Benefit & 3 & 3.00 & 5.00 & 4.9444 & 0.91793 \\
\hline Average On User Interface & 3 & 3.00 & 4.83 & 3.6667 & 1.15470 \\
\hline Valid N (listwise) & 3 & & & & \\
\hline
\end{tabular}

The fact that young adult respondents prioritize the quality of information is very interesting and relevant to the fact that respondents used smartphones for finding information. The needs of quality of information as the main variable are also indicated by the respondents at the age of above $40 \mathrm{yr}$. Meanwhile, the young users or the ones with the range of $30 \mathrm{yr}$ to $40 \mathrm{yr}$ put more emphasis on the ease of use.

From Table 9, it was seen that two variables of most important for most ranges of age are quality of information and ease of access. As for those with the range of age between $30 \mathrm{yr}$ to $40 \mathrm{yr}$, user interface besides the quality of information is considered as important.

The different expectations between the respondents who have or have never donated are the next pattern to be studied. The survey shows that there are no differences in expectations between the two types of respondents. They both consider the quality of information, ease of access and the reliability at the third place. The next thing to be learned is the different expectations between those who have donated 
TABLE 9: Descriptive statistics for users at $30 \mathrm{yr}$ to $40 \mathrm{yr}$

\begin{tabular}{|l|c|c|c|c|c|} 
& N & Minimum & Maximum & Mean & Std. Deviation \\
\hline Average on Ease & 29 & 2.83 & 5.00 & 4.2874 & 0.47538 \\
\hline Average on Quality & 29 & 3.00 & 5.00 & 4.1724 & 0.48486 \\
\hline Average on Benefit & 29 & 2.83 & 5.00 & 4.1149 & 0.46740 \\
\hline Average on User Interface & 29 & 3.17 & 5.00 & 4.0632 & 0.47017 \\
\hline Average on Reliability & 29 & 3.00 & 5.00 & 4.0517 & 0.54025 \\
\hline Valid N (listwise) & 29 & & & & \\
\hline
\end{tabular}

using coupons, box donation and the one who has never donated. This research is focused on the expectations of the respondents who have never donated with the hope that there will be more people who would like to donate. The respondents who have donated using coupons or box donation consider ease of access is more important than the quality of information as second of importance. Those who have never donated, seem to think they would like to find information first, then decide to donate or not. They also expect ease of information access. The same pattern is seen at the respondents who have donated or never donated via the website of The Indonesian Red Cross. For the respondents who have donated using the website of The Indonesian Red Cross, the ease of access is the main variable, then the quality of information. While for those who have never donated, quality of information becomes the variable most expected.

Based on the above analysis, the Indonesian Red Cross Donation Application, first of all, has to pay attention to the quality of information as the main variable expected by the respondents, especially those who have never donated to the Indonesian Red Cross. The application has to be designed to give reliable information. Therefore, the application should limit the access for those users who can contribute information and be able to use the concept of open information exchange. At the other side, the application is expected to be able to provide the most current information, which is quite difficult to be provided if the number of information providers is limited. Thus an application should be designed with the involvements of quite a many numbers of reliable and registered volunteers who can provide information beside the administrator of the Indonesian Red Cross. The application should also be able to show the latest information related to the balance between the amount of donation transferred and the needs of funds for the natural disaster.

The second most important variable is the ease of access. The application designed, should be able to easily access, easy to do the transaction, easy to understand using 
simple language or clear symbols and have payment gateway feature. Providing high quality of information, but easy to access for the users is an interesting challenge. It is also a challenge of itself, as for how to link the information with the feature of payment gateway which is linked to the bank.

The result of the survey indicates that the quality of information and ease of access are the two variables expected by the users for developing the Indonesian Red Cross Donation Application. It shows that before the decision of giving a donation, the users have to be convinced first whether their funds are needed by searching the information they need at the application, not at other applications. They expect the information is reliable. The second variable which is considered important is ease of access in giving a donation. The application developed should provide interesting and reliable information first to attract the users then show updated information with dates and hours. Then there is also direct access to the process of donation that can be seen and followed easily.

\section{Conclusion}

This research tries to develop a Donation Application for The Indonesian Red Cross using a mobile device. In the effort of developing an effective mobile device application, characteristics of the user candidates as respondents of the survey, have to be put into consideration. The respondents are represented by the community in Surabaya, the second biggest city in Indonesia with quite a big number of smartphone users. The questionnaires were distributed randomly to 100 respondents in various range of ages.

The result of the initial research is very interesting as there have been not so many people giving a donation via website, though their willingness to donate is very strong. The huge participation of the society in giving a donation is also indicated by the number of respondents who gave a donation via coupons and donation box of the Indonesian Red Cross, which scope of information distribution is very limited. Therefore, this Mobile Device Donation Application for the Indonesian Red Cross has a big prospect and is very possible to be run effectively. To be able to have an easy and wide range of access, the expectations of the user candidates have to be analyzed. The survey conducted shows that the user candidates expect that the application could provide information of quality, in continuity and ease of access. It is quite a challenge to develop an application with having an effective interaction between the application and the users.

Based on the survey, the interaction most expected by the users is the quality of information which means that the application can provide reliable and up to date 
information. Therefore, the application has to be designed with information on the front page and keep the quality of the information by limiting the users who could provide information. Those who provide information should be front liners in taking care of the logistics of the disaster, as the ones who know best of the situation. The second expected interaction is the ease of access to the process of donating. Therefore, the application should be designed with access to the process of donating being placed on the same page with the information provided, to make it easy for the respondents to give a donation. Based on this research, the next step is to design the application based on the above survey. Then the design has to be analyzed against the expectation of the user candidates to guarantee the effectiveness of the application in meeting the expectation.

\section{References}

[1] Alnanih R, Ormandjieva O. Mapping $\mathrm{HCl}$ principles to design quality of mobile user interfaces in healthcare applications. Procedia Computer Science 2016; 94:75--82. https://www.sciencedirect.com/science/article/pii/S1877050916317549

[2] Widyadana GA, Setiabudi DH, Harsono V, Wongso RC. New disaster aid information system model for Indonesia red cross: a case study in East Java Province. International Journal of Supply Chain Management 2018; 7(3):9--15. https://ojs. excelingtech.co.uk/index.php/IJSCM/article/view/1904

[3] lqbal M. App download and usage statistics [Online] from https://www. businessofapps.com/data/app-statistics/ (2018). [Accessed on 26 July 2018]

[4] Lazar J, Feng JJ, Hochheiser H. Research methods in human-computer interaction. 2nd ed. Morgan Kaufmann, USA; 2017. p. 17 https://www.elsevier.com/books/ research-methods-in-human-computer-interaction/lazar/978-0-12-805390-4

[5] Hsiao CH, Chang JJ, Tang KY. Exploring the influential factors in continuance usage of mobile social Apps: Satisfaction, habit, and customer value perspectives. Telematics and Informatics 2016; 33(2): 342--355. https://www.sciencedirect.com/ science/article/abs/pii/S0736585315001136

[6] Serra LC, Carvalho LP, Ferreira LP, Vaz JBS, Freire AP. Accessibility evaluation of e-government mobile applications in Brazil, Procedia Computer Science 2015; 67: 348--357. https://www.sciencedirect.com/science/article/pii/S1877050915031257

[7] Web Content Accessibility Guidelines Working Group. Web content accessibility guidelines (WCAG) 2.0, https://www.w3.org/TR/WCAG20/ (2008). [Accessed 26 July 
2018]

[8] Burkart C, Besiou M, Wakolbinger T. The funding--humanitarian supply chain interface. Surveys in Operations Research and Management Science 2016; 21(2):31-45. https://www.sciencedirect.com/science/article/pii/S1876735416300149

[9] Naguirney A, Salarpur M, Daniele P. An integrated financial and logistical game theory model for humanitarian organizations with purchasing costs, multiple freight service providers, and budget, capacity and demand constraints. International Journal of Production Economics 2019; 212:212--226. https://www.sciencedirect. com/science/article/abs/pii/S0925527319300544

[10] Fathalikhani S, Hafezalkotob A, Soltani R. Government intervention on cooperation, competition, and coopetition of humanitarian supply chains. SocioEconomic Planning Science 2019. https://www.sciencedirect.com/science/article/ abs/pii/S0038012118303288 